\title{
Author Correction: Twelve-month specific IgG response to SARS-CoV-2 receptor-binding domain among COVID-19 convalescent plasma donors in Wuhan
}

Cesheng Li, Ding Yu, Xiao Wu, Hong Liang, Zhijun Zhou, Yong Xie, Taojing Li@, Junzheng Wu (1D, Fengping Lu, Lu Feng, Min Mao, Lianzhen Lin, Huanhuan Guo, Shenglan Yue, Feifei Wang, Yan Peng, Yong Hu, Zejun Wang, Jianhong Yu, Yong Zhang, Jia Lu, Haoran Ning, Huichuan Yang, Daoxing Fu, Yanlin He, Dongbo Zhou, Tao Du, Kai Duan, Demei Dong, Kun Deng, Xia Zou, Ya Zhang, Rong Zhou, Yang Gao, Xinxin Zhang \& Xiaoming Yang (1)

Correction to: Nature Communications https://doi.org/10.1038/s41467-021-24230-5, published online 6 July 2021.

The original version of this Article contained an error in the abstract, which incorrectly read 'The level of RBD-IgG decreases with time, with the titer stabilizing at $64.3 \%$ of the initial level by 9 month'. The correct version replaces this sentence with 'The level of RBD-IgG decreases with time, with the titer stabilizing at $35.7 \%$ of the initial level by the 9th month'. This has been corrected in both the PDF and HTML versions of the Article.

Published online: 05 August 2021

(c) (i) Open Access This article is licensed under a Creative Commons Attribution 4.0 International License, which permits use, sharing, adaptation, distribution and reproduction in any medium or format, as long as you give appropriate credit to the original author(s) and the source, provide a link to the Creative Commons license, and indicate if changes were made. The images or other third party material in this article are included in the article's Creative Commons license, unless indicated otherwise in a credit line to the material. If material is not included in the article's Creative Commons license and your intended use is not permitted by statutory regulation or exceeds the permitted use, you will need to obtain permission directly from the copyright holder. To view a copy of this license, visit http://creativecommons.org/licenses/by/4.0/.

() The Author(s) 2021 